\title{
The interrelationships among some associative learning tasks
}

\author{
ROBERT A. MALMI \\ State University of New York, Binghamton, New York 13901 \\ BENTON J. UNDERWOOD \\ Northwestern University, Evanston, Illinois 60201 \\ and \\ JOHN B. CARROLL \\ University of North Carolina at Chapel Hill, Chapel Hill, North Carolina 27541
}

\begin{abstract}
The purpose of this study was to determine if associative learning tasks involve two or more relatively independent factors (as suggested by an earlier study). To that end, 12 tasks were constructed; 3 were "standard" (paired associate, free recall, serial), and the others represented transition tasks between the standard tasks. The purpose was to see if factors (as determined by a factor analysis) changed in a meaningful way as the transition was made from one task to another. Some response units were single words, some were word triads; some of the word triads were meaningless, some formed sentences. Paired associate lists also differed in terms of the number of response terms to be associated with a single stimulus term. The 12 tasks were learned by 97 subjects. Two relatively stable highly correlated factors emerged, one involving free recall and serial tasks, the other involving paired associate tasks. This does not confirm the earlier work; the reason for this discrepancy is not known. Again, however, the data emphasized the importance of individual differences in associative learning in contrast to the relatively minor role of the Subject by Task interaction.
\end{abstract}

A recent factor analysis of the performance scores from a wide variety of verbal learning tasks showed that free recall learning on the one hand, and serial and paired associate learning on the other, were associated with two different factors (Underwood, Boruch, \& Malmi, 1978). This was puzzling in that all three tasks seem to require the development and utilization of associations, although just what the associations develop between may be debatable. However, the puzzle is present only if it is assumed that all associative learning is the same in kind regardless of the tasks in which the associations are developed. To say this another way, the puzzle is present only if it is assumed that there are no qualitative differences in associations. It may be that the associations that develop in free recall learning are qualitatively different from those that develop in serial and paired associate learning. The present study was designed to explore this possibility. The approach was to develop transition tasks that in terms of the requirements imposed for learning fell between the "pure" tasks. Thus, as an ostensible paired

This research was supported by the Personnel and Training Research Programs, Psychological Sciences Division, Office of Naval Research, under Contract N00014-76-C-0270, Contract Authority Identification NR 154-371. Reproduction in whole or in part is permitted for any purpose of the United States government. associate task becomes more and more like a free recall task, the factor loadings should shift if the associations for the two pure tasks are qualitatively different. It seemed possible, furthermore, that if associations can be qualitatively different, some of the transition tasks might produce unique factors.

In the previous study, the different tasks were constructed without particular concern for the words used. Thus, it is possible that the words used in constructing the free recall lists differed on a number of characteristics from those used to construct the serial and paired associate lists. As a consequence, it is at least remotely possible that word differences and not task differences were responsible for the appearance of two factors. Two steps were taken in the present study to deal with this issue. First, the words used for all tasks were drawn randomly from the same pool. Second, to examine the role of task difficulty per se, the learning of unrelated words formed into triads was compared with the learning of three words forming a telegraphic sentence.

\section{METHOD}

\section{General Procedure}

All lists, except those using three-word sentences, were formed by drawing words randomly from a pool consisting of all five-letter words listed in Thorndike and Lorge (1944). This 
pool included the words occurring less than once per million. As a consequence, some very uncommon words were included (e.g., hawse, tinct, durst). Each sentence used consisted of three words of four, five, and six letters. As many irregular verbs as possible were used in constructing the sentences to minimize the number of "ed" endings. Three illustrations of the three-word sentences are: "Jogger lost medal," "Girl drove donkey," "Robber took jewel."

As will be described shortly, there were 12 different types of lists. All lists were presented for two study-test trials by lantern slides, and there were always two lists of each type. The test trials were always $90 \mathrm{sec}$ in length. The order of the words differed on each study trial except for the serial lists, where the order was constant. The data sheets for the free recall lists and for the serial lists contained as many numbered blanks as there were words (or triads or sentences) in the list. For the paired associate lists, the stimulus terms were given with a blank after each for the subject to insert the response term. If a stimulus term occurred more than once in a list, it was printed the appropriate number of times on the test sheet.

Lists

The nature of each list will be described. For each, a symbol will be given that will subsequently be used in tables of data.

FR1. These were standard free recall lists consisting of 24 words. Each word was shown for $4 \mathrm{sec}$ on the study trials.

FR3. These tasks consisted of eight triads (e.g., fairy gourd udder) that resulted from the random drawing from the pool of five-letter words. The triads could be recalled in any order chosen by the subject. The three words within a triad did not need to be written in the order presented for study; the only requirement was that the three words had to be written together to be counted correct. All of these requirements were made clear in the instructions. On the study trial, each triad was shown for 12 sec.

FRS. There were 12 sentences, each shown for $6 \mathrm{sec}$ on the study trials. The requirements for recall were the same as for FR3.

SL1. These were serial lists consisting of 24 words, each word being shown for $4 \mathrm{sec}$ during study. The subjects were required to order the words properly on the test trials.

SL3. These were serial lists of eight word triads, each triad being presented for $12 \mathrm{sec}$ on each trial. The subjects were instructed that the triads had to be recalled in the order shown on the study trials, but that the words within each triad need not be given in the order shown.

SLS. These were serial lists of 12 sentences, each exposed for 6 sec. The sentences had to be recalled in the order shown on the study trials.

PA1. These standard paired associate lists consisted of 24 pairs, each shown for $4 \mathrm{sec}$ on the study trial.

PA3. These were eight-pair lists in which the response terms consisted of word triads. The subject was required to pair a triad with its appropriate stimulus term, but the order of the words within the triad was not specified. The study period for each pair was 8 sec.

PAS. These lists were the same as PA3 except the response terms were sentences. The exposure period for each sentence on the study trials was $8 \mathrm{sec}$.

PA-12St. These lists consisted of 24 pairs, but there were only 12 stimulus terms, hence each stimulus term had two different response terms paired with it. The exposure period was $4 \mathrm{sec} /$ pair.

PA-4St. Only four different stimuli were used in these 24-pair lists, hence six different response words were paired with each stimulus term. The exposure period was $4 \mathrm{sec}$.

PA-2St. These 24-pair lists had only two different stimuli, each was paired with 12 different response terms. The exposure duration was $4 \mathrm{sec}$.

\section{Subjects}

Data were obtained on 97 subjects. These college students appeared on 5 consecutive days at the same hour each day and were paid $\$ 15$ for their services. None of the subjects was a psychology major, none was taking the elementary psychology course, and all had English as the native language. The 12 lists described above were learned during the first 4 days, 3 lists/day, and in the order described. The work done on Day 5 was not pertinent to the present problem. The subjects were tested in groups of from 3 to 11 .

\section{RESULTS AND DISCUSSION}

The results will be handled in two steps. The data in Table 1 summarize the learning scores and provide evidence on the reliability of the tasks. Word triads and sentences were scored as correct only when all three words constituting a triad or sentence were given. The learning scores are summarized by the means in the column labeled "Mean Number Correct." A mean was determined for each subject, this value being the mean of the four trials (two trials on each of two tasks), and the value given in Table 1 represents the mean of the 97 means. Two facts are of interest. First, the learning was faster for sentences than for word triads. Three comparisons show this, namely, FR3 vs. FRS, SL3 vs. SLS, and PA3 vs. PAS. In each case the percent correct (based on number possible) is greater for the sentences than for the triads. The second fact worth noting is the substantial reliability of the scores. The correlations shown represent the relationships between the scores on the first list and those on the second, and they range from .56 to .87 , with an average of .72 .

The intercorrelations among the 12 tasks are given in Table 2. The scores on which these correlations were based were the means across all four trials of a given type of task. As can be seen, the intercorrelations are generally high. This fact, plus the fact that the initial analysis showed the first eigenvalue to be 8.35 and the second to be .76 , led to the expectation that we were dealing with only one factor. A maximum-likelihood

Table 1

List Symbols, Number of Items, Mean Correct Responses, and Reliability for the 12 Lists

\begin{tabular}{lcrc}
\hline $\begin{array}{c}\text { List } \\
\text { Symbols }\end{array}$ & $\begin{array}{c}\text { Number of } \\
\text { Items }\end{array}$ & $\begin{array}{c}\text { Mean Number } \\
\text { Correct }\end{array}$ & Reliability \\
\hline FR1 & 24 & 13.52 & .75 \\
FR3 & 8 & 4.52 & .56 \\
FRS & 12 & 7.79 & .65 \\
SL1 & 24 & 9.40 & .56 \\
SL3 & 8 & 3.93 & .75 \\
SLS & 12 & 7.17 & .73 \\
PA1 & 24 & 11.01 & .87 \\
PA3 & 8 & 2.88 & .63 \\
PAS & 12 & 8.18 & .79 \\
PA-12St & 24 & 11.44 & .86 \\
PA-4St & 24 & 11.21 & .78 \\
PA-2St & 24 & 10.82 & .73 \\
\hline
\end{tabular}


Table 2

Intercorrelations Among the 12 Lists

\begin{tabular}{lcccccccccccc}
\hline & FR1 & FR3 & FRS & SL1 & SL3 & SLS & PA1 & PA3 & PAS & PA-12St & PA-4St & PA-2St \\
\hline FR1 & & 68 & 66 & 56 & 65 & 58 & 69 & 56 & 59 & 67 & 64 & 56 \\
FR3 & 68 & & 76 & 55 & 79 & 67 & 74 & 63 & 65 & 72 & 66 & 60 \\
FRS & 66 & 76 & & 49 & 65 & 70 & 66 & 52 & 72 & 63 & 59 & 61 \\
SL1 & 56 & 55 & 49 & & 68 & 57 & 57 & 53 & 46 & 60 & 53 & 50 \\
SL3 & 65 & 79 & 65 & 68 & & 73 & 75 & 70 & 67 & 70 & 66 & 63 \\
SLS & 58 & 67 & 70 & 57 & 73 & & 72 & 60 & 72 & 65 & 63 & 66 \\
PA1 & 69 & 74 & 66 & 57 & 75 & 72 & & 83 & 84 & 87 & 78 & 74 \\
PA3 & 56 & 63 & 52 & 53 & 70 & 60 & 83 & & 71 & 76 & 69 & 63 \\
PAS & 59 & 65 & 72 & 46 & 67 & 72 & 84 & 71 & & 72 & 70 & 65 \\
PA-12St & 67 & 72 & 63 & 60 & 70 & 65 & 87 & 76 & 72 & & 87 & 78 \\
PA-4St & 64 & 66 & 59 & 53 & 66 & 63 & 78 & 69 & 70 & 87 & & 84 \\
PA-2St & 56 & 60 & 61 & 50 & 63 & 66 & 74 & 63 & 65 & 78 & 84 &
\end{tabular}

Note-Loadings on oblique reference axes; decimals omitted.

analysis was carried out with orthogonal rotation, and only a single factor was identified.

The initial report of this outcome was given at a conference attended by the third author. He pointed out to the first two authors that when factors are highly correlated, the unity-eigenvalue rule can be misleading. For example, as shown by Gorsuch (1974, p. 148), a correlation matrix generated from a three-dimensional "box plasmode" yielded only one common factor by this rule. As formulated by Guttman (1954), the unityeigenvalue rule was intended to suggest only a lower bound for the number of common factors. The third author then proceeded to reanalyze the data. The analyses were iterated for communalities on the basis of either two or three factors from principal component solutions. Each of the solutions was then rotated to simple structure by graphical procedures. Table 3 shows the loadings on oblique reference vectors. The third factor appeared too weak to justify its retention. It could be argued that the first nine tasks constitute a complete design in which paradigm is crossed with response-term variations. However, the relationships changed but little when only the scores on the nine tasks were analyzed, so the results for the 12 tasks are shown in Table 3. The correlation between the two factors was .85 .

The free recall and serial tasks constitute one factor, the paired associate tasks the other factor. This does not replicate the earlier study (Underwood et al., 1978), which showed that free recall tasks constituted a factor and serial and paired associate tasks constituted a second factor. We do not know why the difference between the two studies should arise. Perhaps what appear to be relatively minor differences in materials and procedures are involved. It is, perhaps, more important to emphasize similarities rather than differences. As noted earlier, the two factors in Table 2 were highly correlated, a result that implies that there are large and stable individual differences in learning performance that
Table 3

Results of Oblique Rotations for the 12 Variables

\begin{tabular}{lcc}
\hline Variable & Factor A & Factor B \\
\hline FR1 & 34 & 07 \\
FR2 & 48 & -03 \\
FRS & 49 & -06 \\
SL1 & 31 & 06 \\
SL3 & 45 & 02 \\
SLS & 39 & 05 \\
PA1 & 16 & 35 \\
PA3 & 10 & 34 \\
PAS & 24 & 22 \\
PA-12St & 02 & 48 \\
PA-4St & -05 & 53 \\
PA-2St & 02 & 43 \\
\hline
\end{tabular}

Note-Decimals omitted.

tend to override differences attributable to interactions with particular tasks. In the earlier report it was argued that these stable individual differences overrode differences due to interactions between certain word characteristics (e.g., concreteness) and individual differences. In the general sense, then, perhaps the lack of agreement between the two studies is not of great importance. Nevertheless, it is interesting that individual differences interacting with task characteristics can still be identified despite the large amount of variance common to all of the variables.

\section{REFERENCES}

Gorsuch, R. L. Factor analysis. Philadelphia: Saunders, 1974.

Guttman, L. Some necessary conditions for common factor analysis. Psychometrika, 1954, 19, 149-161.

THORNDIKE, E. L., \& LORGE, I. The teacher's word book of 30,000 words. New York: Columbia University Press, 1944.

UNDERWood, B. J., BorUCH, R. F., \& MALMI, R. A. The composition of episodic memory. Journal of Experimental Psychology: General, 1978, 107, 393-419.

(Received for publication January 15, 1979.) 